\title{
Silver-Bismuth Bilayer Anode for Perovskite Nanocrystal Light-Emitting Devices
}

\author{
Xinyu Shen, ${ }^{+}$Xiang Zhang, ${ }^{+}$Chengyuan Tang, ${ }^{+}$Xiangtong Zhang, ${ }^{+}$Po Lu, ${ }^{+}$Zhifeng Shi, ${ }^{\ddagger}$ Wenfa \\ $\mathrm{Xie}^{\dagger}{ }^{\dagger}$ William W. Yu, ${ }^{*, \S}$ Yu Zhang*, ${ }^{\dagger}$
}

†State Key Laboratory of Integrated Optoelectronics and College of Electronic Science and Engineering, Jilin University, Changchun 130012, China

${ }^{\ddagger}$ Key Laboratory of Materials Physics of Ministry of Education Department of Physics and Engineering Zhengzhou University Zhengzhou 450052, China

$\S$ Department of Chemistry and Physics, Louisiana State University, Shreveport, LA 71115, USA 


\section{EXPERIMENTAL SECTION}

Materials. $\mathrm{CS}_{2} \mathrm{CO}_{3}(99.9 \%)$ was obtained from J\&K Chemicals. Oleic acid (OA, 90\%), octadecene (ODE, 90\%) and lead (II) iodide $\left(\mathrm{Pbl}_{2}, 99.999 \%\right)$ were bought from Sigma-Aldrich. Lead (II) bromide $\left(\mathrm{PbBr}_{2}, 99 \%\right)$, ethyl acetate (99\%), oleylamine (OLA, 70\%) and zinc (II) iodide $\left(\mathrm{ZnI}_{2}, 99.99 \%\right)$ were purchased from Aladdin. Toluene (99.5\%) was obtained from Beijing Chemical Factory. All chemicals were used directly without further purification.

Preparation of cesium oleate. $\mathrm{Cs}_{2} \mathrm{CO}_{3}(0.814 \mathrm{~g}, 2.5 \mathrm{mmol})$, was loaded into a $100 \mathrm{~mL}$ 3-neck flask along with $30 \mathrm{~mL} O D E$ and $2.5 \mathrm{~mL} \mathrm{OA}$, dried under vacuum for $1 \mathrm{~h}$ at $120^{\circ} \mathrm{C}$. Then the mixture was heated to $150{ }^{\circ} \mathrm{C}$ under $\mathrm{N}_{2}$ and was kept for $3 \mathrm{~h}$ until all $\mathrm{Cs}_{2} \mathrm{CO}_{3}$ reacted with OA. It was preheated to $100{ }^{\circ} \mathrm{C}$ before injection because Cs-oleate precipitated out of ODE at room-temperature.

Synthesis of $\mathrm{CsPb}_{1-\mathrm{x}} \mathrm{Zn}_{\mathbf{x}} \mathrm{l}_{3}$ PNCs. $\mathrm{Pbl}_{2}(0.260 \mathrm{~g}, 0.564 \mathrm{mmol}), \mathrm{ZnI}_{2}(0.180 \mathrm{~g}, 0.564 \mathrm{mmol}$ ) and ODE (30 mL) were added into a $100 \mathrm{~mL}$ 3-neck flask and dried under vacuum for $1 \mathrm{~h}$ at $120{ }^{\circ} \mathrm{C}$ and then heated under $\mathrm{N}_{2}$ at $120^{\circ} \mathrm{C}$. At the same time, OLA ( $3 \mathrm{~mL}$ ) and OA ( $\left.3 \mathrm{~mL}\right)$ were injected into the system. 10 min later, the temperature was increased to $170{ }^{\circ} \mathrm{C}$ and Cs-oleate solution $(2.4 \mathrm{~mL}, 0.37 \mathrm{mmol}$ ) was quickly injected and after $5 \mathrm{~s}$ the solution was immediately cooled down to room temperature by immersing the flask in an ice water bath.

Synthesis of CsPbX ${ }_{3}$ PNCs. 0.376 mmol PbX ${ }_{2}\left[\mathrm{Pbl}_{2}\right.$ (0.173g) for $\mathrm{CsPbl}_{3}, \mathrm{PbBr}_{2}(0.046 \mathrm{~g}, 0.125$ $\mathrm{mmol}$ ) and $\mathrm{Pbl}_{2}(0.115 \mathrm{~g}, 0.251 \mathrm{mmol})$ for $\left.\mathrm{CsPbBrl}_{2} \mathrm{PNCs}\right]$ and $\mathrm{ODE}(10 \mathrm{~mL})$ were added into a $50 \mathrm{~mL}$ 3-neck flask and dried under vacuum for $1 \mathrm{~h}$ at $120^{\circ} \mathrm{C}$ and then heated under $\mathrm{N}_{2}$ at $120^{\circ} \mathrm{C}$. Meanwhile, OLA $(1 \mathrm{~mL})$ and $\mathrm{OA}(1 \mathrm{~mL})$ were injected into the system under the protection of $\mathrm{N}_{2}$. After $10 \mathrm{~min}$, the temperature was increased to $170{ }^{\circ} \mathrm{C}$ and Cs-oleate $(0.8$ $\mathrm{mL}, 0.123 \mathrm{mmol}$ ) was quickly injected and $5 \mathrm{~s}$ later the solution was immediately cooled down to room temperature by immersing the flask in an ice water bath.

Purification. The crude product was purified by centrifuging for $10 \mathrm{~min}$ at $7000 \mathrm{rpm}$; the supernatant containing unreacted precursors and byproducts was discarded. The precipitate was dispersed in a mixture of toluene and ethyl acetate (volume ratio of toluene:ethyl 
acetate $=1: 3$ ) forming stable colloidal solutions for further characterization. The PNCs were purified by centrifuging at $10000 \mathrm{rpm}$ for $8 \mathrm{~min}$ and the supernatant was discarded. Then the PNCs were dispersed in toluene.

Fabrication of LEDs. Indium tin oxide (ITO) substrates were cleaned by immersing in ethanol and acetone with ultrasonic agitation and then by UV-ozone treatment for $10 \mathrm{~min}$. A solution of ZnO NCs (20 mg mL-1) was spin-coated onto the ITO glass at $1000 \mathrm{rpm}$ for $40 \mathrm{~s}$ and annealed in air at $200^{\circ} \mathrm{C}$ for $10 \mathrm{~min}$. Then, the substrate was transferred into a $\mathrm{N}_{2}$ gas filled glovebox. A solution of polyethyleneimine (PEI) (dissolve in 2-methoxyethanol, 0.2\% mass ratio) was spin coated onto the $\mathrm{ZnO}$ film at a speed of $3000 \mathrm{rpm}$ and annealed at $125^{\circ} \mathrm{C}$ for $10 \mathrm{~min}$. PNC active layers $\left(20 \mathrm{mg} \mathrm{mL}^{-1}\right)$ were spin cast from toluene dispersion at 1000 rpm. 4,4',4"-Tris(carbazol-9-yl)-triphenylamine (TCTA), $\mathrm{MoO}_{3}, \mathrm{Bi}$ and $\mathrm{Ag}$ were then sequentially deposited by thermal evaporation in a vacuum deposition chamber $\left(1 \times 10^{-7}\right.$ Torr).

Characterizations. The morphology of the PNCs was observed with a JEM-2100F transmission electron microscope (TEM). X-ray diffraction (XRD) patterns were acquired using a Bruker D8 Advance $X$ diffractometer ( $C u K \alpha, \lambda=1.5406 \AA$ ). Absorption spectra were measured using a Shimadzu UV-2550 spectrophotometer. The PL spectra of the PNCs and the EL spectra of LEDs were measured using an Ocean Optics spectrometer. X-ray photoelectron spectroscopy (XPS) was done on an ESCALAB250 spectrometer. The complex impedance measurements of the sensors were performed by using an impedance analyzer (Solartron 1260 and Solartron 1287) in the frequency range of $1 \mathrm{~Hz}-1 \mathrm{MHz}$. The amplitude of the AC potential signal was fixed at $140 \mathrm{mV}$ and the applied bias voltage was set as $0.5 \mathrm{~V}$. A Keithley 2612B source meter was used to measure the current-voltage characteristics of the devices. The LED brightness was determined using a Photo Research Spectra Scan spectrometer PR655. 


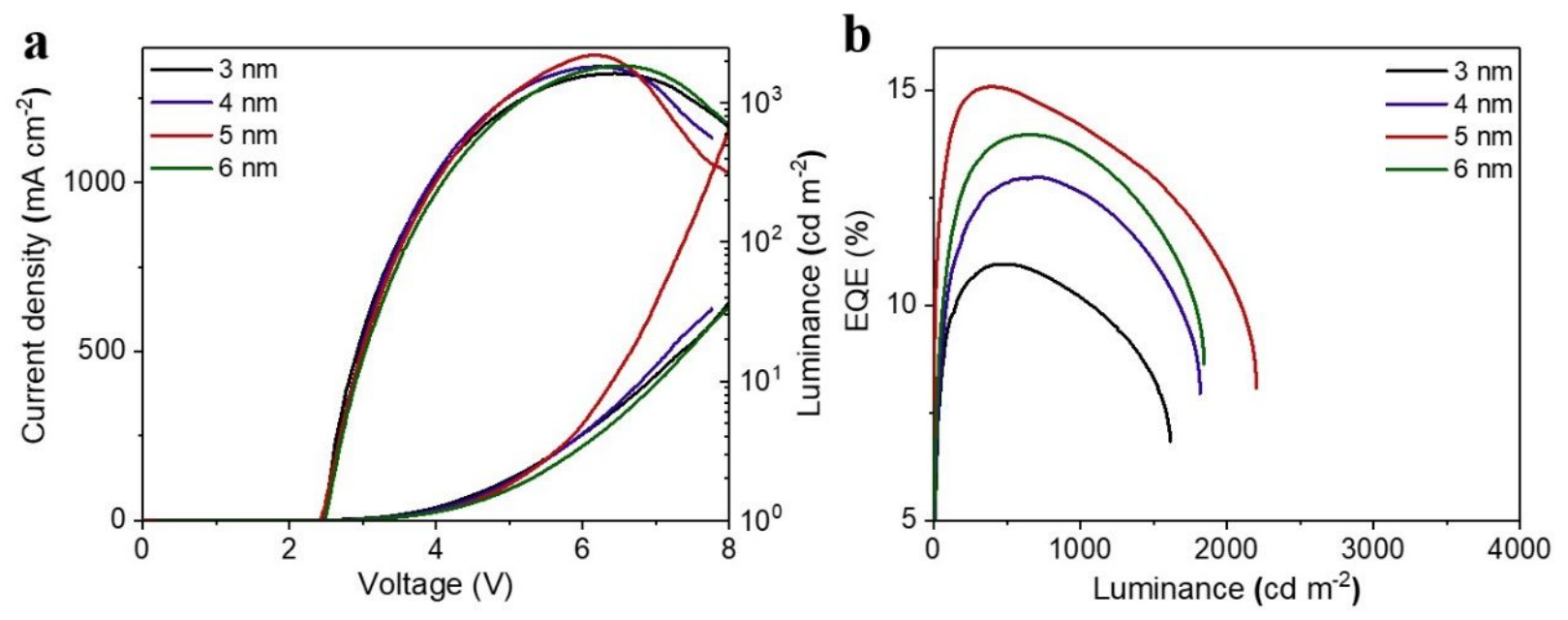

Figure S1. Influences of $\mathrm{MoO}_{3}$ thickness in LEDs with Ag monolayer anode. a) J-V-L and (b) EQE curves for CPZI PNC LEDs with Ag monolayer anode.
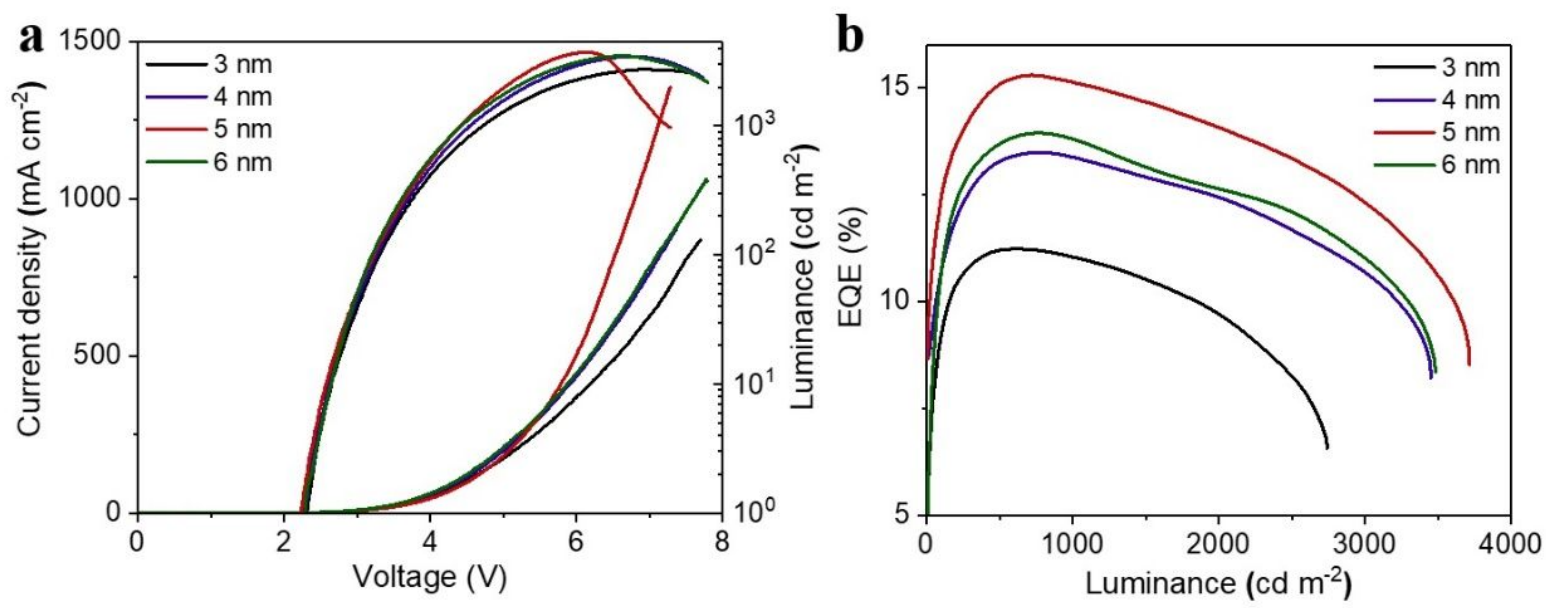

Figure S2. Influences of $\mathrm{MoO}_{3}$ thickness in LEDs with Ag-Bi bilayer anode. a) J-V-L and (b) EQE curves for CPZI PNC LEDs with Ag-Bi bilayer anode. 


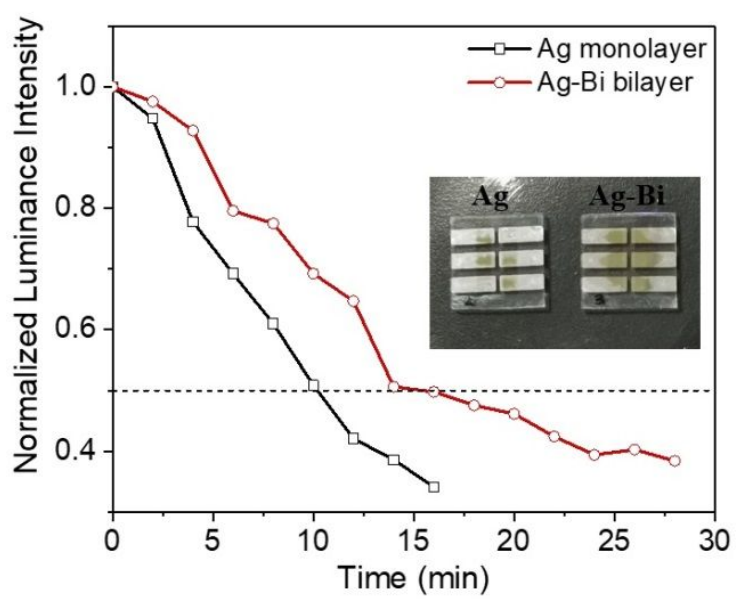

Figure S3. Stability tests for LEDs with Ag monolayer and Ag-Bi bilayer anode under $10 \mathrm{~mA} \mathrm{~cm}^{-2}$. The inset shows the photos of devices with $\mathrm{Ag}$ monolayer and Ag-Bi bilayer anode aged in air after a month.
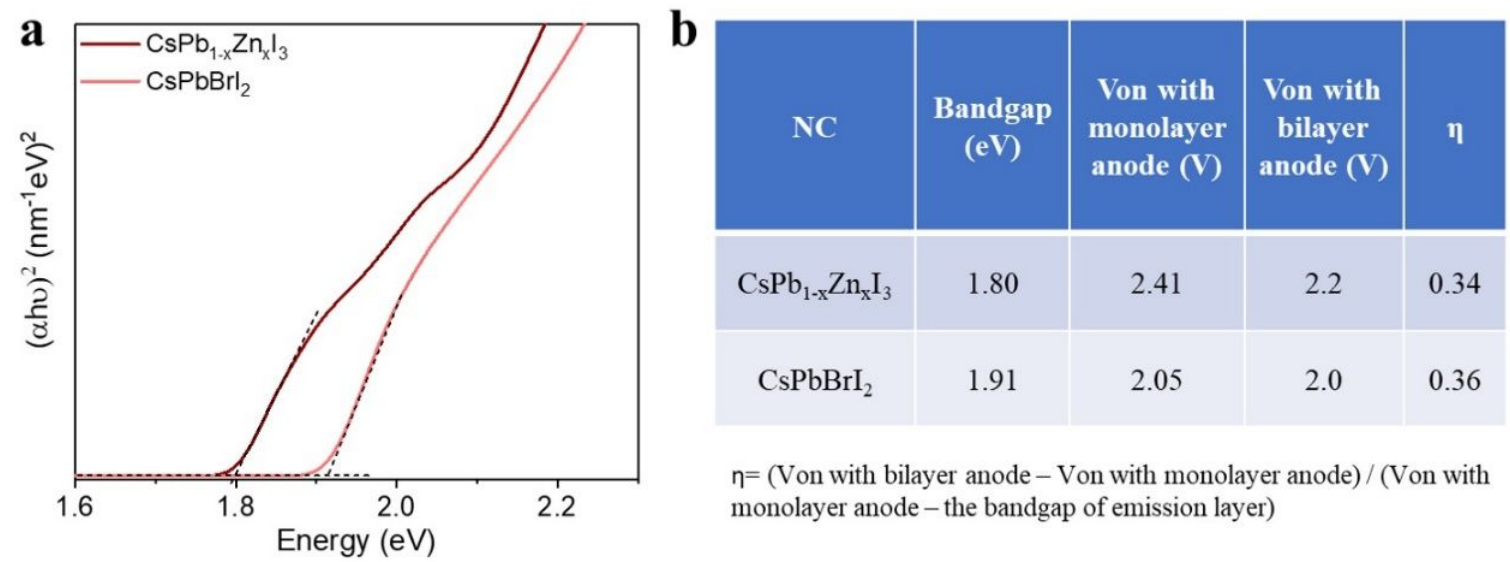

Figure S4. a) Bandgaps of PNCs used in the manuscript. b) Turn on voltage $\left(\mathrm{V}_{\mathrm{on}}\right)$ for different PNC LEDs with Ag monolayer anode and Ag-Bi bilayer anode. 